\title{
Biliary rendezvous through the gallbladder using a lumen-apposing metal stent
}

Endoscopic ultrasound (EUS)-guided rendezvous is a feasible and safe technique to provide biliary access when endoscopic retrograde cholangiopancreatography (ERCP) fails [1,2]. Recently, EUS-guided gallbladder stent deployment has been used as an alternative drainage method [3]. Local treatment of biliary perforations aims to divert bile and allow spontaneous wound healing [4]. We describe a modified biliary rendezvous technique using a transmural gallbladder stent.

A 41-year-old woman presented with upper abdominal pain, nausea, and vomiting. Laboratory tests showed abnormal liver function tests, with normal bilirubin, and abdominal ultrasound displayed gallstones and a dilated common bile duct (CBD). EUS revealed choledocholithiasis ( Fig.1). During ERCP, a prophylactic plastic stent was placed due to inadvertent guidewire insertion into the pancreatic duct. However, after five attempts of biliary cannulation, intraprocedural perforation (Stapfer type II) was suspected. To avoid biliary leakage, EUS-guided gallbladder drainage was performed, using a linear echoendoscope, and a lumen-apposing metal stent (Hot AXIOS, $15 \times 10 \mathrm{~mm}$; Boston Scientific, Marlborough, Massachusetts, USA) was deployed between the duodenal bulb and the gallbladder ( Fig. 2). Following the procedure, the patient was started on intravenous antibiotics. The patient showed clinical improvement in a few days, although mild cholestasis was still observed at discharge.

As shown in $>$ Video 1 , a second procedure was performed. Using a gastroscope, under fluoroscopic control, a hydrophilic 0.035 inch guidewire was introduced through the gallbladder lumen until the papilla was reached ( $\downarrow$ Fig. 3 , -Fig.4). The duodenoscope was then introduced over the guidewire and biliary cannulation and sphincterotomy were achieved ( $>$ Fig. $\mathbf{5}$ ). No remaining choledocholithiasis was observed. During the

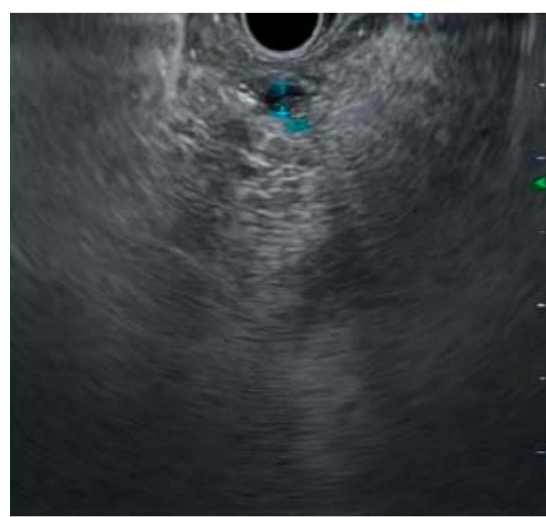

-Fig. 1 Endoscopic ultrasound showed lithiasis in the common bile duct.

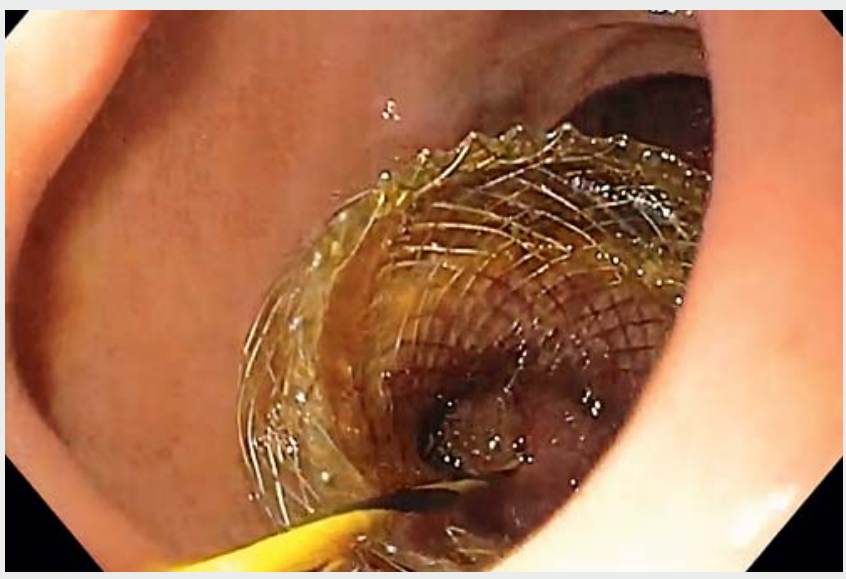

Video 1 A rendezvous procedure was accomplished by inserting a guidewire through a previously deployed gallbladder lumen-apposing metal stent. After the papilla was reached, over-the-guidewire biliary cannulation was performed. same procedure, the stent was removed with a biliary stent extractor and the transmural tract was closed using an over-the-scope clip (OTSC System Set $12 / 6$ mm, type t; Ovesco Endoscopy AG, Tübingen, Germany). After stent removal, the patient was referred for cholecystectomy.

Endoscopy_UCTN_Code_TTT_1AS_2AG
Competing interests

The authors declare that they have no conflict of interest. 


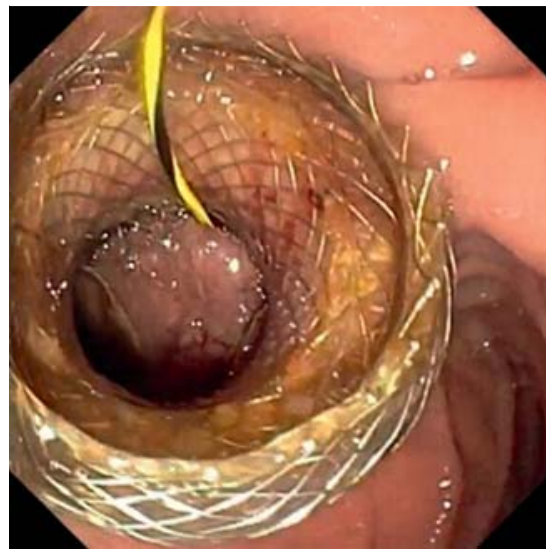

- Fig. 3 Endoscopic view of guidewire introduction using the gallbladder stent.

The authors

Margarida Flor de Lima $\uparrow_{\text {, Nuno Nunes, Diogo }}$ Bernardo Moura, Carolina Chálim Rebelo @ Vera Costa Santos, José Renato Pereira, Maria Antónia Duarte

Gastroenterology Department, Hospital do Divino Espírito Santo de Ponta Delgada EPE, Ponta Delgada, Portugal

\section{Corresponding author}

\section{Margarida Flor de Lima, MD}

Gastroenterology Department, Hospital do Divino Espírito Santo de Ponta Delgada EPE, Avenida D. Manuel I Matriz, 9500 - 370

Ponta Delgada, Portugal

margaridaflordelima@hotmail.com

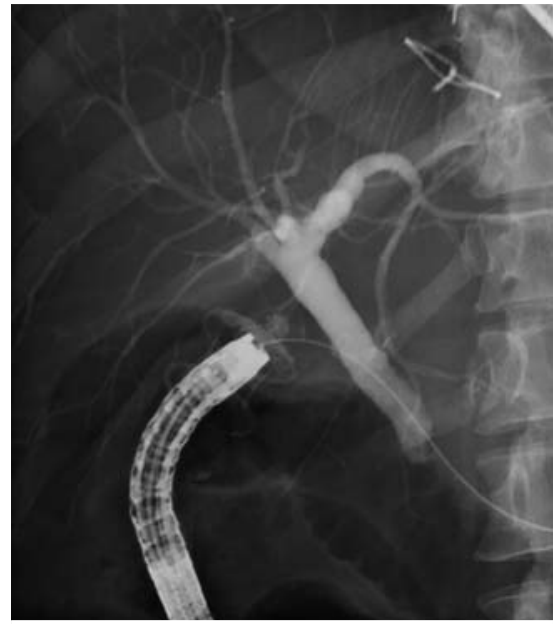

> Fig. 4 Cholangiography and visualization of the guidewire through the papilla.

\section{References}

[1] Mallery S, Matlock J, Freeman ML. EUS-guided rendezvous drainage of obstructed biliary and pancreatic ducts: report of 6 cases. Gastrointest Endosc 2004; 59: 100-107

[2] Iwashita T, Yasuda I, Mukai T et al. EUSguided rendezvous for difficult biliary cannulation using a standardized algorithm: a multicenter prospective pilot study (with videos). Gastrointest Endosc 2016; 83: 394400

[3] Teoh AYB, Kitano M, Itoi T et al. Endosonography-guided gallbladder drainage versus percutaneous cholecystostomy in very highrisk surgical patients with acute cholecystitis: an international randomised multicentre controlled superiority trial (DRAC 1). Gut 2020; 69: 1085-1091

[4] Paspatis GA, Arvanitakis M, Dumonceau J et al. Diagnosis and management of iatrogenic endoscopic perforations: European Society of Gastrointestinal Endoscopy (ESGE) Position Statement - Update 2020. Endoscopy 2020; 52: 792-810

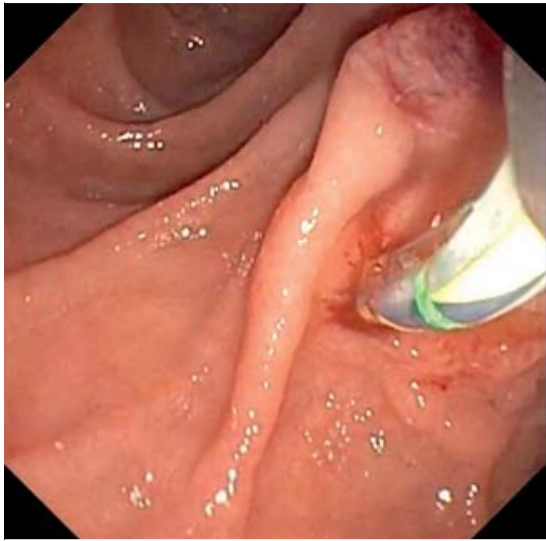

Fig. 5 Biliary cannulation and sphincterotomy.

\section{Bibliography}

\section{Endoscopy 2022; 54: E312-E313}

DOI $10.1055 / \mathrm{a}-1525-1461$

ISSN 0013-726X

published online 9.7.2021

(c) 2021. Thieme. All rights reserved. Georg Thieme Verlag KG, Rüdigerstraße 14, 70469 Stuttgart, Germany

\section{ENDOSCOPY E-VIDEOS}

https://eref.thieme.de/e-videos

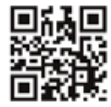

Endoscopy E-Videos is an open access online section, reporting on interesting cases and new techniques in gastroenterological endoscopy. All papers include a high quality video and all contributions are freely accessible online. Processing charges apply (currently EUR 375), discounts and wavers acc. to HINARI are available.

This section has its own submission website at

https://mc.manuscriptcentral.com/e-videos 